\title{
Role of Women in Agriculture-A Review
}

Yuvraj Kasal*, Poonam Shete and Pravin Dahiphale

\author{
School of Agriculture, Lovely Professional University, Phagwara, Punjab, India
}

*Corresponding author

\section{A B S T R A C T}

\section{Keywords}

Feminisation, Agriculture, Wages, Farming

\section{Article Info}

Accepted:

23 April 2020

Available Online:

10 May 2020
The number of female-headed households is increasing as a result of civil wars. The IAASTD describes this as 'the feminisation of agriculture' that is having profound and far-reaching effects, both positive and negative. Compared to men, women and girls are still more severely affected by poverty, hunger and disease. When food is scarce, female family members often get the smallest portions. On the labour market, women are literally paid starvation wages. Mothers also suffer most from lack of medical care and balanced diets. The responsibility for the survival of their children commonly demands additional sacrifices from them. In Africa and large parts of Asia, women in rural areas bear the main responsibility for taking care of children and elderly. They also constitute the majority of the agricultural labour force in small-scale and subsistence farming.

\section{Introduction}

Mainly rural women are engaged in agricultural activities in three different ways depending on the socio-economic status of their family and regional factors. They work as: Paid Labourers, Cultivator doing labour on their own land, Managers of certain aspects of agricultural production by way of labour supervision and the participation in postharvest operations.

\section{Types of agricultural activities taken up by women include the following}

Sowing, Nursery management, Transplanting, Weeding, Irrigation, Fertilizer application, Plant protection, Harvesting, winnowing, storing etc. Livestock is the primary livelihood activity used to meet household food needs as well as supplement farm incomes. It is a common practice in the rural areas to give an animal as part of a women's dowry. Studies have revealed rural women 
earn extra income from the sale of milk and animals. Mostly women are engaged in cattle management activities such as Cleaning of animal and sheds, Watering of cattle, Milking the animals, Fodder collection, Preparing dung cakes, Collection farm yard manure.

Except grazing, all other livestock management activities are predominantly performed by women. Men, however, share the responsibility of taking care of sick animals. It is evident that the women are playing a dominant role in the livestock production and management activities.

Poultry farming is one of the major sources of rural economy. The rate of women participation in poultry farming at household level is central in poultry industry.

Economic Survey 2017-18 says that with growing rural to urban migration by men, there is 'feminisation' of agriculture sector, with increasing number of women in multiple roles as cultivators, entrepreneurs, and labourers. Globally, there is empirical evidence that women have a decisive role in ensuring food security and preserving local agro-biodiversity. Rural women are responsible for the integrated management and use of diverse natural resources to meet the daily household needs. This requires that women farmers should have enhanced access to resources like land, water, credit, technology and training which warrants critical analysis in the context of India. In addition, the entitlements of women farmers will be the key to improve agriculture productivity. The differential access of women to resources like land, credit, water, seeds and markets needs to be addressed.

With women predominant at all levelsproduction, pre-harvest, post-harvest processing, packaging, marketing - of the agricultural value chain, to increase productivity in agriculture, it is imperative to adopt gender specific interventions. An 'inclusive transformative agricultural policy' should aim at gender-specific intervention to raise productivity of small farm holdings, integrate women as active agents in rural transformation, and engage men and women in extension services with gender expertise.

Rural women form the most productive work force in the economy of majority of the developing nations including India. More than $80 \%$ of rural women are engaged in agriculture activities for their livelihoods. About 20 per cent of farm livelihoods are female headed due to widowhood, desertion, or male emigration. Agriculture support system in India strengthens the exclusion of women from their entitlements as agriculture workers and cultivators. Most of the womenheaded households are not able to access extension services, farmers support institutions and production assets like seed, water, credit, subsidy etc. As agricultural workers, women are paid lower wage than men.

The "Mahila Kisan Sashaktikaran Pariyojana" (MKSP), a sub component of the Deendayal Antodaya Yojana-NRLM (DAY-NRLM) seeks to improve the present status of women in Agriculture, and to enhance the opportunities available to empower her.

MKSP recognizes the identity of "Mahila" as "Kisan" and strives to build the capacity of women in the domain of agro-ecologically sustainable practices. It has a clear vision to reach out to the poorest of poor households and expand the portfolio of activities currently handled by the Mahila Kisan.

The focus of MKSP is on capacitating smallholders to adopt sustainable climate resilient agro-ecology and eventually create a pool of skilled community professionals. Its 
objective is to strengthen smallholder agriculture through promotion of sustainable agriculture practices such as Community Managed Sustainable Agriculture (CMSA), Non Pesticide Management (NPM), Zero Budget Natural Farming (ZBNF), PashuSakhi model for doorstep animal care services, Sustainable regeneration and harvesting of Non-Timber Forest Produce.

MKSP intervention strategy involves building a structure on the foundation of sustainability. This involves incorporating climate change resilient and ecologically sound practices into the overall structure. Community Resource Persons (CRPs) play a proactive role in scaling up these initiatives. Major interventions promoted under DAY-NRLM which contribute to climate change resilience and risk mitigation among the poor are:

Community managed sustainable agriculture (agro-ecology approaches), Usage of locally available natural inputs - for pest management and soil fertility management, System of root intensification - SRI, SCI, Promotion of millets and cereal crops, Promotion of multiple crops, Tree based farming practices, Regeneration of forest species, Usage of locally available natural inputs, Integrated farming practice with small ruminants, Convergence with MGNREGA to create agriculture assets for the community, Non Pesticide Management, Natural soil fertility Management, Integrating livestock with agriculture, Integration of livestock promotion of Pashusakhi model, Ensuring the scalability of climate change resilient agriculture practices through Community Best Practitioners (CBPs), In-situ rain water harvesting.

The program is being implemented by DAY NRLM in partnership with State Rural Livelihood Missions/ Community Based Organizations

(CBOs)/NGOs, implementing partners (PIAs) across the country. These agencies are expected to support and nurture scalable livelihood models in the MKSP intervention areas. In the process, it is expected that a cadre of barefoot community professionals will be created from among the best practitioners. The State Rural Livelihood Missions will further replicate the models with the help of the community.

Gender, that is socially constructed relations between men and women, is an organizing element of existing farming systems worldwide and a determining factor of ongoing agricultural restructuring. Current trends in agricultural market liberalization and in the reorganization of farm work, as well as the rise of environmental and sustainability concerns are redefining the links between gender and development. The proportion of women in agricultural production and postharvest activities ranges from 20 to $70 \%$; their involvement is increasing in many developing countries, particularly with the development of export-oriented irrigated farming, which is associated with a growing demand for female labor, including migrant workers.

Whereas these dynamics have in some ways brought benefits, in general, the largest proportion of rural women worldwide continues to face deteriorating health and work conditions, limited access to education and control over natural resources, insecure employment and low income. This situation is due to a variety of factors, including the growing competition on agricultural markets which increases the demand for flexible and cheap labor, growing pressure on and conflicts over natural resources, the diminishing support by governments for small-scale farms and the reallocation of economic resources in favor of large agroenterprises. Other factors include increasing exposure to risks related to natural 
disasters and environmental changes, worsening access to water, increasing occupational and health risks.

\section{Female participation in agriculture in} India

Women as farmers, laborers and entrepreneurs are the driving force of India's farmland. According to OXFAM 2018, agriculture sector employs $80 \%$ of all economically active women in India, they comprise $33 \%$ of the agriculture labour force and $48 \%$ of the self-employed farmers. In spite of their large contribution women continue to remain invisible in the rural economy of India.

The country has witnessed massive agricultural distress during the past couple of years. Farmers from major agriculture dependent states have come on streets to protest against the low price for farm produce and demanding loan waiver. Major participants of these protests were women farmers and their unattended demands. Limited access to resources, illiteracy, land allocation for farming and recognition is consistently adding trouble for women farmers. The vicious cycle of debt, crop failure and poverty often force them to take their own lives. According to NCRB, out of the total 8,007 farmer suicides in 2014, 441 were by women farmers and cultivators. Among the suicides by Agricultural laborers, 577 were women. The agony of the women farmers needs to be heard both at the policy and implementation level. In order to make women farmers capable, access to information on advanced agricultural practices is needed. Women bear the burden of getting paid with low wages compared to men. Policy emphasis must be to recognise the work of female farmers and grant equal pay to them. Lack of land rights is one of the crippling issues for women farmers. There is an urgent need to change the inheritance practices and give land rights to daughters as well. Further, to increase efficiency and promote sustainable agricultural practices, skill development training needs to be delivered to women farmers. Skill development programs will train women farmers in areas of field operations, organic farming etc. Technological advancements in designing tools can play an important role in making farm equipment easy to use for women. Majority of women in the rural sector are involved in animal husbandry, hence imparting veterinary knowledge to women can result in better results. Self-help groups have been playing a crucial role in improving the status of women in rural villages. Such self-help groups can help women farmers by providing financial support in terms of loans and promote best agricultural practices through training. Fair support price has been the major demand of farmers all over the country. In order to provide a fair price and direct market linkages, Mahila Kisanmandis should be promoted for women farmers where they can sell their produce without any hassle.

According to the United Nations Food and Agricultural Organisation, if women had the same access to productive resources as men, they could increase yields on their farms by $20-30 \%$. If we want the agricultural sector to thrive in the country, acknowledging the contribution of women farmers becomes an absolute necessity. We need to provide them with opportunities and upgrade their skills through collective training and capacity building programs.

\section{Development strategies for women in the rural economy and farming}

Recent years have seen women, with their individual educational backgrounds, professionalism and skills, contributing to the further development of traditional rural 
lifestyles and business models. They are, at one and the same time, the stabilising and the modernising force in such types of business, and that makes them indispensable in the sustainable development of rural areas. This applies particularly in agriculture - a sector where women have made a substantial contribution in recent years to business diversification and adjustment to the market, thereby advancing the practical outworking of the sector's multifunctionality. Farm businesses, by virtue of the innovative products and services they offer as well as their own output, remain a cornerstone of local food supply in rural areas. There is scope for utilising the types of economic potential represented here to an even greater extent than was previously possible with CAP second-pillar funding. In this context, there are opportunities to provide practical support measures for women in agriculture. Greater account must be taken of the wide range of vocational skills, interests and achievements of women, so that jobs in farming remain an attractive option for them. This will entail women having a full share in the resources that underpin farming as a way of life and a type of business. Women farmers must have a share in rights and duties that is commensurate with their co-responsibility for the farm business, including through the representation of interests on agricultural bodies and by having a real share in farm income. Ensuring adequate social cover for all women who work in agriculture is another indispensable factor in modern sustainable farming. Experience with systems of agricultural social security in the EU Member States should be taken into account and should, in the medium term, contribute to a definite improvement of the social situation of women in agriculture.

\section{References}

1.Acharaya, M., and Bennett, L. (1982). Womgn and kth Subsistence Sector, Economic Participation ad Household Decision-making i\& Ne2al. World Bank Staff Working Paper, (526).

2.Budlender, D. (2008). The statistical evidence on care and non-care work across six countries (No. 4). Geneva: United Nations Research Institute for Social Development.

3.Government of India. 2006. Employment and Unemployment Situation in India 2004-05, part I and II. Report No. 515 (61/10/01). National Sample Survey Organisation, Ministry of Statistics and Programme Implementation, Government of India

4.Vargas Hill, R., and Vigneri, M. (2011). Mainstreaming gender sensitivity in cash crop market supply chains.

5.Pereira, L., and Juan, M. (2017). Social And Solidarity Economics In India And Brazil. Social Enterprise Journal.

\section{How to cite this article:}

Yuvraj Kasal, Poonam Shete and Pravin Dahiphale. 2020. Role of Women in Agriculture - A Review. Int.J.Curr.Microbiol.App.Sci. 9(05): 2946-2950.

doi: https://doi.org/10.20546/ijcmas.2020.905.349 